\title{
Estudo de superfície de ouro funcionalizadas utilizando AFM
}

\author{
Juliana A. F. Burguim*, Paula S. Casagrande, David M. Soares.
}

\section{Resumo}

Neste trabalho utilizaremos o AFM para estudar duas funcionalizações sobre o ouro, uma hidrofílica utilizando ácido 3mercaptopropiônico e uma hidrofóbica utilizando octanotiol. Em ambos os casos notamos um aumento significativo da rugosidade bem como alterações na molhabilidade. Estas funcionalizações podem ser empregadas, futuramente, no controle de corrosão ou em sistema "drug delivery".

\section{Palavras-chave:}

AFM, ouro, funcionalização.

\section{Introdução}

A molhabilidade descreve a capacidade que um líquido tem de contatar uma superfície. $\mathrm{O}$ grau de molhabilidade resulta de um balanço enrte forças intermoleculares de coesão entre as moléculas do líquido e de adesão com o sólido. ${ }^{1}$

Neste trabalho fizemos monocamadas autoformadas hidrofóbicas (octanotiol) e hidrofílicas (ácido 3mercaptopropiônico) sobre um substrato policristalino de ouro. Utilizamos a técnica de microscopia de força atômica (AFM) para estudar estas funcionalizações.

\section{Resultados e Discussão}

O AFM é uma técnica de varredura por sonda altamente empregada para o estudo de superfícies em escala nanométrica, que permite obter características intrínsecas do material analisado, bem como suas ligações químicas. A interação da ponta de prova com a amostra pode ser atrativa ou repulsiva, gerando deflexões, que movimentam o cantilever proporcionando imagens tridimencionais da superfície, capaz de chegar a uma escala atômica, com uma área de varreduras micrométricas. $^{2}$

Assim, utilizando esta técnica realizou-se imagens de AFM, com dimensão de $2 \mathrm{~mm} \times 2 \mathrm{~mm}$, do ouro sem funcionalização e do ouro com funcionalização hidrofóbica e hidrofílica. A formação dos filmes hidrofóbicos foi feita através da imersão do substrato em $5 \mathrm{ml}$ de etanol com monômeros de octanotiol $(0,1 \mathrm{mM})$, durante um período de 24 horas. De forma similar a solução hidrofílica foi feita com monômeros de ácido 3mercaptopropiônico (3-MPA) $(0,1 \mathrm{mM})$.

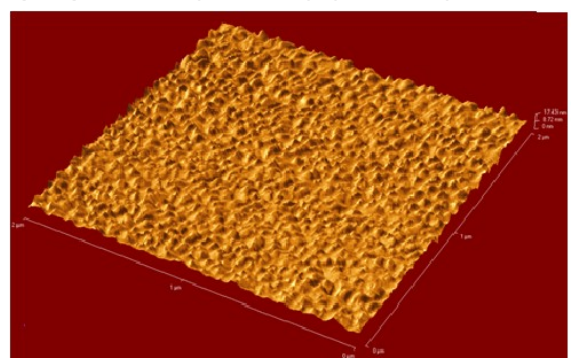

Figura 1. Imagem de AFM do substrato de ouro, rugosidade média $1,6652 \mathrm{~nm}$.
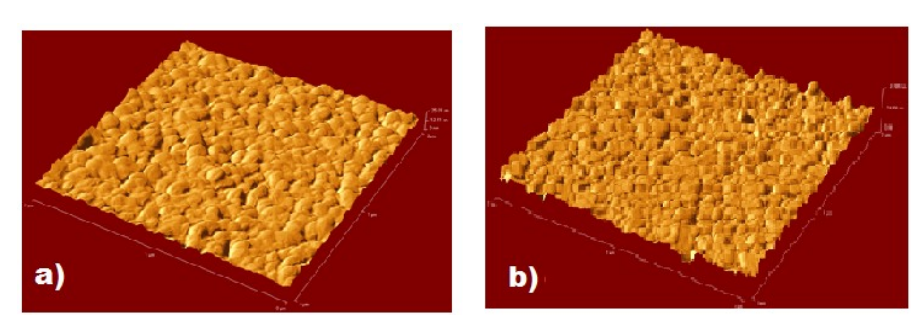

Figura 2. Imagens do ouro funcionalizado feitas pelo AFM a) filme octanotiol rugosidade média 2,0017nm; b) filme de 3-MPA, rugosidade média 2,3934nm.

Comparando as figuras 1 e 2 nota-se que há um aumento da rugosidade em relação ao substrato de ouro. Essa mudança na superfície mostra que há formação dos dois filmes sobre o ouro. Por fim, realizamos medidas do ângulo de contato da superfície com líquido e observamos que o ouro tem um carácter ligeiramente hidrofóbico que aumenta com o filme de octanotiol e muda com a funcionalização do 3-MPA, resultando em uma superfície hidrofílica.

\section{Conclusão}

Com os resultados apresentados notamos que a técnica de crescimento de filmes utilizadas nos permitiu obter filmes aderentes. As medidas do AFM mostraram que a rugosidade da superfície aumenta para ambos os filmes. Medidas do ângulo de contato mostram mudanças na molhabilidade com o filme de 3-MPA na superfície de ouro, tornando-a hidrofílica. Estas funcionalizações podem ser empregadas, futuramente, no controle de corrosão, sistemas de "drug delivery",etc.

\section{Agradecimentos}

P.S.C. é bolsista Capes e J.A.F.B. é bolsista SAEUnicamp. Agradecimentos ao Dr. Wyllerson E. Gomes.

\footnotetext{
${ }^{1}$ Oliveira, Márcio Roberto da Silva Superfícies Super-Hidrofóbicas obtidas através de Microestruturas Litografadas. 2011. 125 f. Tese (Doutorado Engenharia Elétrica) - Escola Politécnica da USP, Universidade de São Paulo, São Paulo.

${ }^{2}$ Giessibl, Frazz. J. Advances in atomic force microscopy. Augsburg, ano 2003, n. 3, Vol. 75 , p. $949-983$
} 